\title{
ARENDT, A FENOMENALIDADE E A POLÍTICA: O PROBLEMA DA APARÊNCIA
}

\section{ARENDT, THE PHENOMENALITY AND POLITICS: THE PROBLEM OF APPEARANCE}

Helton Adverse*

\begin{abstract}
RESUMO
A partir da noção de fenomenalidade, o artigo tem por objetivo examinar como se configuram no pensamento arendtiano as relações entre política e aparência. Para tanto, retoma rapidamente o sentido dessa expressão em $A$ vida do espírito, isolando em seu núcleo o conceito de pluralidade para, em seguida, examinar algumas de suas consequências políticas. Como pano de fundo, se identifica o problema da relação de Arendt com a fenomenologia.
\end{abstract}

PALAVRAS-CHAVE: Arendt. Política. Fenomenologia. Fenomenalidade. Aparência.

\begin{abstract}
This article's purpose is to examine the relations between politics and appearance in Hannah Arendt's thought, beginning with the notion of phenomenality. To achieve this goal, I associate this notion with the concept of plurality in Arendt's last work The life of the mind and I try to analyze some of its most important political consequences. The relation between Arendt end the phenomenological tradition can be identified as the backdrop of this paper.
\end{abstract}

KEYWORDS: Arendt. Politics. Phenomenology. Phenomenality. Appearance.

\section{Introdução}

Hannah Arendt definiu a si mesma, em certa ocasião, como "uma espécie de fenomenóloga, mas não à maneira de Hegel - ou de Husserl” (ARENDT apud YOUNGBRUEHL, 1982, p. 531). Em contrapartida, em uma entrevista bastante conhecida, ela declarou de modo peremptório que não pertencia "ao círculo dos filósofos" nem se sentia como um deles (ARENDT, 1994, p. 1). Entre uma declaração e outra há uma aparente

\footnotetext{
* Professor Associado do Departamento de Filosofia da UFMG. E-mail: heltonadverse@ @otmail.com
} 
contradição: na primeira ela parece reivindicar sua inscrição em uma tradição filosófica - a fenomenologia (mesmo reconhecendo o caráter problemático dessa inscrição) -, ao passo que na segunda ela parece simplesmente recusar qualquer inscrição e reivindicar uma posição de completa exterioridade. Essa aparente contradição levanta uma série de questões a respeito da relação de Arendt com a filosofia: ela pertence ou não a essa tradição? Fazemos justiça ao pensamento arendtiano quando o consideramos uma forma de filosofia ou deveríamos tomá-lo como uma antifilosofia ou ainda uma crítica radical da filosofia? E, finalmente, Arendt é uma autora inclassificável ou valeria a pena realizar o esforço de inseri-la em uma tradição de pensamento? Muitos comentadores se debruçaram sobre essas questões e suas respostas, como era de se esperar, soam divergentes (TAMINIAUX, 1992; ABENSOUR, 2006 e 2014; LE NY, 2013). Meu propósito, neste texto, não é o de enfrentar essas questões, muito menos tomar partido na disputa que divide os especialistas de Arendt acerca do status de sua obra (filosofia ou crítica da filosofia). E está longe de minhas intenções e capacidades escrever mais um capítulo sobre a relação de Arendt com a complexa tradição da Fenomenologia ${ }^{1}$ (embora esta questão seja também abordada). Meu objetivo é outro: dirigindo o olhar para um tema recorrente na obra de Arendt - a saber, a relação entre ser e aparecer ou, ainda, àquilo que ela denomina de fenomenalidade - gostaria de mostrar que ela articula uma reflexão política extremamente original a partir da tradição fenomenológica e em contraposição à filosofia política clássica, servindo-se, portanto, da própria filosofia contra a filosofia. Arendt está, portanto, ao mesmo tempo dentro e fora da tradição filosófica. Se disso resulta uma nova filosofia política, este é uma problema que escapa a meu horizonte investigativo.

\section{Uma Herança Fenomenológica.}

Das complexas relações entre Arendt e a fenomenologia, valeria a pena reter um elemento: a crítica, já presente em Husserl, à clássica distinção metafísica entre ser e aparecer. O conceito husserliano de fenômeno, na medida em que explicita a relação entre o que aparece e a consciência, rompe com a concepção metafísica de aparência, que pressupõe um dualismo no qual o aparecer está subordinado ao ser. Desta ruptura, Arendt irá retirar um enorme benefício, radicalizando-a em um sentido preciso: é necessário operar um deslocamento da questão do ser em direção àquela da aparência, isto é, privilegiar o problema

\footnotetext{
${ }^{1}$ Acerca deste tópico, muito já foi escrito, especialmente no que concerne à relação de Arendt com Heidegger, como vemos em nas obras de J. Taminiaux (1992), D. Villa (1996), A. Duarte (2010) e M. Le Ny (2013).
} 
da fenomenalidade, pois é o único modo de compreendermos a especificidade da vida política. Este deslocamento implica, primeiramente, a destituição da separação entre ser e aparência, ou ainda, ele requer a crítica das ilusões metafísicas produzidas pela tradição filosófica, as quais têm em seu núcleo a hipótese de que o mundo verdadeiro se encontra para além daquilo que é conhecido no mundo fenomênico. Mas qual o sentido desta crítica da metafísica? Para Arendt, é preciso entender que a duplicação da realidade entre ser e aparência, na qual o primeiro constitui o fundamento do segundo, está a serviço do ocultamento do sentido da política. Quando desejamos restituir à vida prática sua autêntica dimensão, somos obrigados a colocar em xeque a pertinência desse modelo de compreensão do mundo, em favor de outro que coloque em primeiro plano a especificidade da ação.

Porém, antes de examinar as consequências “políticas” da crítica à distinção metafísica entre ser e aparecer, é necessário compreender os termos em que ela se formula no pensamento de Arendt e, para isso, poderia ser interessante começar do final, isto é, partir de sua obra mais tardia, A vida do espírito, pois é lá que a crítica encontra sua forma mais madura, e em um contexto em que as referencias à tradição fenomenológica são mais do que mera alusão, especialmente se levarmos em conta a presença constante (mas não determinante) de Merleau-Ponty.

Em que termos Arendt formula, então, sua crítica à metafísica? Arendt escreve no primeiro parágrafo do primeiro capítulo de seu livro com esta proposição "Neste mundo em que entramos, aparecendo de lugar nenhum, e do qual vamos desaparecer em direção a lugar nenhum, Ser e Aparecer coincidem" (ARENDT, 1978, p. 19). Esta afirmação não é de natureza dogmática. Fiel, neste ponto, ao método fenomenológico, Arendt acredita que ela se funda sobre nossas "experiências básicas"2, que nos fazem perceber a fenomenalidade do mundo, o que inclui o reconhecimento de que todos os seres vivos que nele se encontram existem sob a forma do aparecer, do que podemos deduzir que a coincidência entre ser e aparecer indica uma tendência (uma "urgência", diz Arendt) ao aparecer. O ser é o ser que aparece. Isto não somente dissolve uma coisa na outra, mas explicita que a existência é aparecer. E se a existência é aparência, ela implica a presença daquele para quem ela aparece, ou seja, o espectador. Aparecer é aparecer para alguém. Mesmo a matéria morta, inorgânica, diz Arendt, depende, em seu ser, da aparência, logo, "da presença de criaturas vivas" (ARENDT, 1978, p. 19). E no que concerne aos "seres sensientes", os seres humanos e os animais, eles são ao mesmo tempo aparências e os garantidores da aparência, cada um deles

\footnotetext{
${ }^{2}$ Convém notar que essa remissão à "experiência” está presente em toda a obra arendtiana.
} 
sendo capaz de "ouvir e ser ouvido, tocar e ser tocado" (ARENDT, 1978, p. 19). Logo, eles não são meramente sujeitos ou objetos, mas uma coisa e outra. À semelhança do que havia afirmado em A condição humana, a respeito da natureza condicionada e condicionante do ser humano, para Arendt a "mundaneidade (worldliness) das coisas vivas significa que não existe sujeito que não seja também um objeto e não apareça como tal para alguém mais, que garante sua realidade 'objetiva'" (ARENDT, 1978, p. 19).

A partir dessas considerações iniciais, duas coisas devem ser retidas. A primeira é a de que o aparecer, na medida em que requer a presença de um outro sujeito (o qual é também objeto), sempre se perfaz na "pluralidade", quer dizer, pressupõe a existência dos outros. A segunda coisa, estreitamente associada à anterior, é a seguinte: a referência à "pluralidade", em que se realiza a fenomenalidade, desarticula a crença em uma subjetividade ou objetividade absolutas, permitindo a Arendt destacar a dimensão relacional da aparência e, por conseguinte, do próprio mundo. É imprescindível salientar este ultimo ponto por causa de suas consequências políticas, as quais ainda vamos examinar. Pelo momento, ainda é necessário acompanhar de perto o desenvolvimento argumentativo de Arendt em sua cruzada contra a metafísica.

Uma vez que ser e aparecer coincidem, como entender a emergência da falácia que os separa de modo radical? Como entender essa vontade de metafisica que conduz não somente a sua desvinculação mas também à constituição de uma hierarquia, uma subordinação entre uma coisa e outra? Dizendo de outra forma, qual a origem do preconceito contra a superfície? Estas questões, de matiz nietzschiano, são tão mais pertinentes quanto mais evidente é o fato de que nossa experiência cotidiana nos mantém sempre no registro da aparência ${ }^{3}$. E se juntarmos a isso o fato de que nosso "aparato mental" estar naturalmente articulado com as aparências torna-se difícil compreender por que se realizou, na história do pensamento, o corte entre ser e aparecer.

Como era de se esperar, a solução que Arendt vai ensaiar para dar conta dessas dificuldades será, mais uma vez, a identificação de uma "experiência básica", desta feita, a própria experiência do pensar. Esta experiência coloca um problema para a fenomenalidade porque consiste em uma espécie de "morte para o mundo", um afastamento do mundo, que requer uma explicitação em termos fenomenológicos. E é precisamente o que Arendt irá fazer na sequencia de seu livro. Mas, para os propósitos deste trabalho, basta assinalar que essa

\footnotetext{
3 Retomando Merleau-Ponty, diz Arendt que sempre "saímos da aparência para encontrarmos a aparência" (ARENDT, 1978, p. 23).
} 
retirada do mundo está na origem de uma falácia "lógica", a qual fundamenta a falácia metafísica. Levando isso em conta, a experiência do pensar nos interessa porque, como atividade característica do filósofo, conduz a pensar a aparência para além dela mesma. É verdade que o próprio aparecer, como observa Arendt, "sugeriu ao filósofo, isto é, à mente humana, a noção de que algo deve existir e que não é aparência" (ARENDT, 1978, p. 23). Ou ainda: “... quando o filósofo afasta-se do mundo dado aos sentidos e faz uma virada (a periagogê de Platão) em direção ao mundo do espírito, ele pega esta pista do primeiro [isto é, do mundo sensível], procurando por algo que seja revelado a ele e que explicasse sua verdade subjacente" (ARENDT, 1978, p. 23). Aqui fica explicitada a estrutura daquilo que Arendt denomina de "falácia lógica", perfeitamente exemplificada na alegoria da caverna: o impulso de buscar algo que, para além das aparências, lhe sirva de fundamento. Porém, é muito importante estar atento para o fato de que essa falácia não introduz, inicialmente, a noção de uma realidade não aparente para explicar a realidade aparente. O fundamento da aparência é reconhecido, mesmo pelos filósofos de maior inclinação metafísica, como uma outra aparência, um outro fenômeno originalmente escondido, mas de status superior ao fenômeno primeiramente conhecido. Esta outra aparência, mais recôndita e mais verdadeira, adquirirá a primazia ontológica no interior da tradição metafisica sob o nome de Ser. Esta tradição, portanto, nega a evidência do senso comum, pois este é incapaz de distinguir ou de atribuir superioridade ontológica a determinado fenômeno e é neste ponto preciso que, segundo Arendt, a falácia irá se apoiar:

\begin{abstract}
Contra esta inabalável convicção do senso comum se erige a antiga supremacia teórica do Ser e da Verdade sobre a mera aparência, isto é, a supremacia do fundamento, que não aparece, sobre a superfície. Este fundamento supostamente responde à mais antiga questão da filosofia e da ciência: como é possível que algo ou alguém, incluindo a mim mesmo, apareça e o que o faz aparecer sob esta forma ou figura ao invés de outra qualquer? A questão inquire mais por uma causa do que por uma base ou fundamento, mas o que está em jogo é que nossa tradição da filosofia transformou a base a partir da qual algo emerge na causa que o produz e, assim, atribuiu a esse agente um nível mais alto de realidade do que àquilo que meramente aparece para os olhos. A crença de que a causa deve ser de um nível mais alto do que o efeito [...] pertence provavelmente às mais antigas e obstinadas falácias metafísicas (ARENDT, 1978, p. 25).
\end{abstract}

Arendt deixa entender, portanto, que não é a mera desconfiança frente à aparência que está na origem do preconceito metafísico contra o aparecer, mas a convicção de que a dimensão da aparência exige a pressuposição de um principio explicativo que possa conferirlhe plena inteligibilidade. Ora, este principio de inteligibilidade assegura ainda a subsunção de toda a realidade aparente a um princípio de unidade que a transcende e a funda: o Ser. Como 
afirma E. Tassin: “A fenomenalidade do mundo, que compreende com ela a fenomenalidade das existências, exige ser pensada na dimensão da pluralidade. O Ser é um para a metafísica; as aparências são, por definição, plurais” (TASSIN, 1989, p. 93).

É o coração da metafísica que fica exposto nas análises de Arendt. A noção de causalidade é a forma lógica do desejo de subordinação da realidade fenomênica a um princípio ordenador. A busca por este princípio termina por desnaturar a própria compreensão da fenomenalidade e de tudo aquilo que pode ser associado a seu caráter essencial, a saber, a pluralidade. Como já vimos, o aparecer no mundo implica a presença dos outros que são, eles também, sujeitos e objetos da aparição; logo, a fenomenalidade do mundo está sujeita à lei da terra, isto é, à pluralidade (ARENDT, 1978, p. 19; LE NY, 2013, p. 72). Este me parece ser o ponto central das críticas de Arendt à tradição metafísica, o que, aliás, é perfeitamente conforme ao trabalho que desenvolveu ao longo de sua vida. Desde seus estudos sobre o totalitarismo, Arendt se volta contra todas as concepções políticas e filosóficas que pretendem tomar a realidade a partir de um único princípio explicativo. Sua interpretação do mito da caverna, por exemplo, toca neste ponto nevrálgico da filosofia política clássica, ou seja, a tentativa do filósofo de compreender a realidade em geral - e a vida política em particular por meio de noções que servem de medida para a captura da diversidade do mundo. As ideias platônicas cumprem essa função ao se apresentarem como a essência verdadeira de todas as coisas (ARENDT, 1990 e 2005). Não é um acaso a alegoria da caverna ser novamente evocada nesta obra tardia.

Do que acabei de expor, gostaria de reter dois pontos antes de avançar ao segundo momento de minha argumentação. O primeiro deles é o seguinte: Arendt, como era de se esperar, leva a cabo sua própria "fenomenologia" continuando e rompendo com a tradição fenomenológica. Especificamente no que concerne ao tema da dimensão intersubjetiva da fenomenalidade, está clara a continuidade com autores como Merleau-Ponty, pois este, a propósito da percepção, coloca em xeque, desde ao menos A estrutura do comportamento, a tradicional compreensão do mundo em termos da oposição entre sujeito e objeto, em favor, justamente, de uma visão relacional. Arendt também acompanha Merleau-Ponty em seu combate contra os preconceitos metafísicos e, em certa medida, em sua crítica dos conceitos fundamentais da filosofia moderna, dentre eles, obviamente, o de consciência, de imagem e de coisa. Mas o que confere a suas análises seu teor próprio é a compreensão do tema na fenomenalidade a partir da pluralidade. Não estou dizendo que este é o único traço que 
diferencia Arendt da tradição fenomenológica ${ }^{4}$, mas é certamente aquele que permite articular de forma coerente os diversos momentos de sua reflexão sobre a vida ativa e a vida contemplativa (ou seja, de $A$ condição humana até $A$ vida do espírito).

O segundo ponto para o qual desejaria chamar a atenção é a radicalidade com a qual Arendt retoma o problema da aparência. Se a tradição fenomenológica - desde Husserl com sua injunção para "voltarmos às coisas mesmas" - sempre privilegiou o tema da aparência como o locus privilegiado para articular os principais problemas da reflexão filosófica, Arendt, de sua parte, leva a suas últimas consequências o desmantelamento da distinção metafísica entre ser e aparecer, perscrutando com um olhar atento o campo do pensamento filosófico para ver se aí não restaria ainda resíduo de essencialismo. Em outras palavras, ela rejeita explicitamente qualquer teoria que de algum modo, mesmo involuntariamente, restitua as categorias tradicionais sob a máscara de categorias novas como o ego transcendental, por exemplo (TASSIN, 1989, p. 93). Mas não apenas isso. Também é objeto de crítica as tentativas de simplesmente inverter a relação essência/aparência em favor da aparência ou do sensível, como parecem fazer os positivistas. Na sequência de Nietzsche, Arendt recorda que “com o mundo verdadeiro também é abolido o mundo aparente" (ARENDT, 1978, p. 10-11). Dessa forma, a plena compreensão da fenomenalidade requer assumir a inevitabilidade da aparência (sua natureza inultrapassável) ou ainda, como diria Merleau-Ponty, citado por Arendt, "quando uma aparência se desfaz, é sempre em proveito de uma nova aparência [...] não há Schein sem Erscheinung" (ARENDT, 1978, p. 28).

\section{Aparência e Política.}

Que consequências a noção arendtiana de fenomenalidade acarreta no domínio da reflexão política? Para responder a essa questão é necessário, primeiramente, relembrar o teor das crítica que Arendt lança contra a tradição da filosofia política. Em linhas gerais, a filosofia política é responsável pelo ocultamento do verdadeiro sentido da política (ARENDT, 2005). Mais detalhadamente, isso significa que ela operou uma "redução" da experiência política que obedece aos seguintes princípios, denominados por Miguel Abensour (2014) de "esquemas fundadores" da tradição do pensamento político. Ei-los: 1) a redução da polis ao oikos, "o que acarreta imediatamente o apagamento do abismo entre o espaço de liberdade onde a ação é seu próprio fim e um espaço de necessidade orientado para a reprodução da vida, sob a

\footnotetext{
${ }^{4}$ Para uma análise mais detalhada, remeto o leitor a ao trabalho de Le Ny (2013).
} 
autoridade despótica do chefe de família" (ABENSOUR, 2014, p. 173); 2) "a nova dissociação do par archein/prattein - começar e agir - que, no exercício da política no seio da cidade, representava dois momentos estreitamente associados" (ABENSOUR, 2014, p. 173); 3) a "promoção do governo em detrimento da ação", derivado do desejo de estabilidade e de ordem que nutriu a evasão definitiva da política; 4) a "denegação da condição humana de pluralidade" (ABENSOUR, 2014, p. 173-174). A estes quatro esquemas gostaria de acrescentar outro, a saber, 5) a distinção metafísica entre ser e aparecer, destinada a desqualificar a natureza fenomênica da ação e pressupor a existência de uma concepção unificada de verdade. Na impossibilidade de detalhar cada um desses "esquemas fundadores", proponho deter a atenção sobre os dois últimos (4 e 5) porque é em torno dos problemas que articulam que poderemos compreender mais claramente como a noção arendtiana de fenomenalidade viabiliza, ao mesmo tempo, uma crítica da tradição da filosofia política e uma outra forma de reflexão sobre a realidade política.

Um dos elementos centrais da tradição da filosofia política é a identificação do poder com a dominação, a qual foi incansavelmente denunciada por Arendt. Ora, a afirmação da condição humana da pluralidade, assim como a recusa da distinção metafísica entre ser e aparecer - ou seja, aquilo que em $A$ vida do espírito ganha o nome de fenomenalidade - são algumas das diretrizes maiores do projeto arendtiano de restituição do sentido da política, o que implica a desarticulação das bases sobre as quais pôde se assentar essa mesma tradição: as falácias metafísicas, como já foi visto. Mas como exatamente pode a fenomenalidade cumprir essa função? A seguinte passagem de um artigo de Beatriz Porcel é esclarecedora: “O aparecer sempre se oferece a uma pluralidade de perspectivas. Tudo o que aparece não se faz diante de um espectador único capaz de totalizar todos os aspectos. Logo, a fenomenalidade do político é incompatível com uma posição dominante” (PORCEL, 2015, p. 34).

O que significa essa "fenomenalidade do político" é explicitado por Arendt em diversas ocasiões, valendo destacar uma conhecida passagem de seu livro sobre a revolução onde escreve que "no domínio dos assuntos humanos, ser e aparência são na verdade uma única e mesma coisa" (ARENDT, 1990, p. 98). Se não é possível fazer a distinção entre ser e aparência (ou, como Arendt dirá em A vida do espírito, entre "ser e aparecer") no espaço político - definido como espaço para a "aparição" (ARENDT, 1958) -, então ele é identificado como, por excelência, o lugar da doxa, isto é, da opinião. Melhor ainda: o espaço político é aquele em que não temos senão as doxai, as quais se definem por sua parcialidade e reivindicam sua natureza perspectiva (ARENDT, 2005). Doxa, repetirá Arendt inúmeras 
vezes, deriva de dokei moi, ou seja, o "mundo tal qual ele aparece para mim (ARENDT, 2005, p. 15). Esta parcialidade de opiniões corresponde à condição humana da pluralidade e significa, no âmbito político, a impossibilidade de um único indivíduo abarcar a totalidade da realidade, como observou Porcel. E essa negação da totalidade barra a possibilidade de fundamentar a dominação política em uma visão compreensiva, como pretendia a tradição da filosofia política, especialmente a partir de Platão. Dizendo de outra forma, ninguém detêm a visão do todo, ninguém detém um saber sobre o todo e, por conseguinte, ninguém pode fundamentar sua pretensão política sobre esse saber ou sobre a verdade.

A pluralidade de perspectivas erige uma barreira sólida contra todo projeto político de dominação, entendida como a seletividade no acesso ao espaço político e o alheamento dos cidadãos dos processos de tomada de decisão. Sob o signo da doxa, a vida política é, por definição, incompatível com uma visão única da realidade que, na tradição metafísica, costuma ser identificada com a verdade. Esta "verdade racional" ou "filosófica" (ARENDT, 1968, p. 227-232) nega a condição da pluralidade de duas maneiras: primeiramente, a própria noção de verdade filosófica se define como superação das opiniões e, logo, conduz à sua desqualificação epistêmica e política; em segundo lugar, o conhecimento dessa verdade requer o isolamento do filósofo, ou seja, a solidão e o afastamento da cidade necessários à vida contemplativa. Não é difícil perceber o estreito vínculo entre a concepção filosófica de verdade e a falácia metafísica que preconiza a distinção ontológica entre ser e aparecer. Consequentemente, a crítica da segunda está em continuidade com a crítica da primeira. Há, porém, um aspecto do problema que merece ser destacado e a partir do qual será possível mais uma vez atar os laços e, ao mesmo tempo, problematizar a relação de Arendt com a fenomenologia (especificamente com Merleau-Ponty). Trata-se da crítica a um dos aspectos mais distintivos da tradição da filosofia política, especialmente no que concerne a Platão, de constituição de um saber filosófico acerca da política.

Para esclarecer este ponto, gostaria de lembrar que ao examinar o problema da aparência na política Arendt, via de regra, reconhece a grande contribuição de Maquiavel (ARENDT, 1958, p. 35; 1990, p. 101). A concepção maquiaveliana de virtù testemunharia sua sensibilidade à fenomenalidade da política, por exemplo. Mas parece-me importante notar que essa dimensão do pensamento maquiaveliano já é identificada por Merleau-Ponty em um texto que provavelmente Arendt não ignorava, "Nota sobre Maquiavel", escrito para um congresso realizado em Roma e em Florença em setembro de 1949 e publicado inicialmente 
em Signos $(1960)^{5}$, livro que Arendt conhecia, pois o cita em algumas ocasiões. Fundamental neste pequeno texto merleau-pontiano é a passagem em que afirma que "é uma condição fundamental da política desenrolar-se na aparência" (MERLEAU-PONTY, 1989, p. 296). Quando a esta passagem acrescentamos aquela em que Merleau-Ponty afirma que o poder do príncipe jamais se confunde com o fato bruto da dominação ou com um direito absoluto (1989, p. 290), estamos muito próximos do ponto de vista de Arendt. É verdade que a Arendt não interessa as reflexões de Merleau-Ponty acerca do papel do imaginário na vida política. Entretanto, parece inegável que o gesto de Merleau-Ponty é afeito ao de Arendt por, no mínimo, duas razões: 1) Merleau-Ponty acredita que Maquiavel, "colocando no centro de suas descrições a questão da aparência, teria de antemão desenvolvido uma autêntica fenomenologia política" porque o autor de $O$ príncipe, "longe de reconduzir a aparência a uma simples ilusão, a considera em sua consistência própria para dela fazer o lugar próprio e a verdade da ação histórica" (AUDIER, 2005, p. 182). 2) No que concerne à possibilidade de um saber acerca da totalidade política, Maquiavel teria mostrado que o príncipe "não é um sujeito onisciente liberado de todo entrave" (AUDIER, 2005, p. 171) e o povo não poderia ser considerado um puro objeto de conhecimento. O saber sobre a política é necessariamente parcial e não corresponde a um lugar privilegiado que poderia estar ao abrigo da indeterminação; antes, ele é rebatido sobre uma práxis na qual as posições entre sujeito e objeto jamais estão definidas:

Rejeitando o dualismo entre o sujeito do conhecimento e seu objeto, a interpretação merleau-pontiana vê operando aqui uma práxis, e não uma démarche de ordem puramente teórica. Dizendo de outra forma, a política [...] constitui segundo Merleau-Ponty uma experiência na qual observação e ação são indissociáveis (AUDIER, 2005, p. 171).

Os pontos de convergência com Arendt são bastante evidentes. A referência a eles permite esclarecer o que está em jogo nas análises arendtiana: uma espécie de "fenomenologia do político", como quer Myriam Revault d'Allonnes, inspirada em Maquiavel e que desempenha a função primordialmente crítica de uma "máquina de guerra contra a tradição constituída da filosofia política” (REVAULT D’ALLONNES, 2001, p. 181), um instrumento poderoso contra a tentativa de submeter a política a um princípio ordenador que a unificasse e a reduzisse a um objeto de conhecimento. Pensar a política sob a égide da "manifestação",

\footnotetext{
${ }^{5} \mathrm{O}$ texto de Merleau-Ponty foi também publicado em uma coletânea encabeçada por sua aula inaugural no Collège de France, Eloge de la philosophie. É esta edição que utilizo aqui.
} 
como diria Merleau-Ponty, ou da "aparição", como diria Arendt, significa mais do que alterar profundamente nosso modo de compreendê-la; trata-se de abrir uma via que dê acesso a sua autêntica natureza, sem sucumbir ao impulso totalizador da filosofia nem submeter-se a seus esquemas interpretativos redutores. Mas para tanto, é imprescindível fazer como Maquiavel, quer dizer, descentrar o eixo da vida política: o lugar do poder não está mais circunscrito no espaço social como um centro a partir do qual irradia sua verdade. $O$ poder se configura nas relações que se estabelecem no âmbito da comunidade política e, assim como a imagem do príncipe, não é prerrogativa de ninguém nem pode estar sob o controle de ninguém. Como diria Arendt, é no "espaço entre", no inter homines, que a política acontece. Este espaço não é suscetível a ser perscrutado pelo olhar do soberano que deteria o segredo de sua unidade e o fundamento de seu sentido. Impossibilidade, portanto, de construção de um saber acabado, definitivo, totalizador do campo político. Destituição, por conseguinte, da compreensão tradicional do poder - que o definia seja em termos de dominação seja em termos de direito cujo suporte ideológico poderia ser buscado no discurso filosófico.

Além disso, a colocação em xeque da "verdade filosófica" implica a afirmação da radical contingência da vida política ${ }^{6}$. E no que concerne a este caráter contingente, mais uma vez Arendt e Merleau-Ponty se encontram. Mas Arendt vai seguir um caminho próprio, alheia às considerações de Merleau-Ponty, em particular, e à tradição fenomenológica, em geral, ao enraizar a contingencia na natalidade. Como quer que seja, no que diz respeito às diferenças cruciais entre Arendt e Merleau-Ponty, a consideração acerca da imagem em Maquiavel conduz o francês a uma reflexão sobre a dimensão imaginária da política, ao passo que interessa a Arendt enfatizar não exatamente o problema da imagem, mas o que poderíamos chamar de "aspecto constitutivo" da aparência na política.

\section{Conclusão}

É possível compreender a relação entre aparência e política sob dois aspectos diferentes e interligados. Por um lado, o espaço político, o domínio dos "assuntos humanos", como diz Arendt, é o "espaço da aparição", o que significa que aí não cabe distinguir entre o que é e o que aparece. Nesse sentido, a natureza do político é "fenomênica" e, se tomarmos o

\footnotetext{
${ }^{6} \mathrm{O}$ "mundo da aparência", o "espaço da aparição", que não é o lugar da manifestação da verdade, não está submetido à necessidade nem subordinado a regras gerais que determinam o curso dos acontecimentos: uma das preocupações recorrentes de Arendt foi exatamente a de salientar o caráter "eventual" da ação.
} 
status do agente político por referência, somos levados a concluir que sua existência é manifestação. Arendt alarga o horizonte desta tese no final de sua vida, estendendo-a a tudo o que existe no mundo, dando um sentido mais amplo à proposição de que "a pluralidade é a lei da Terra". E ela apenas pôde fazê-lo aprofundando suas críticas à tradição metafísica e retomando, à sua maneira, seus laços com a fenomenologia. Na primeira seção deste trabalho, meu objetivo foi apresentar, em linhas gerais, os termos em que esta compreensão da realidade se estrutura. $\mathrm{Na}$ segunda seção o objetivo era explorar o significado político da tese que afirma a coincidência entre ser e aparecer. E para isso uma nova aproximação com Merleau-Ponty se fez necessário por causa de sua leitura de Maquiavel. Evidentemente, estava fora de questão sugerir uma influência da obra merleau-pontiana sobre Arendt neste tópico, embora ela não possa ser descartada. O que me pareceu mais produtivo foi retomar brevemente determinados aspectos da interpretação de Merleau-Ponty para tornar mais claros os benefícios teóricos que Arendt pôde extrair de Maquiavel. Desses benefícios, um dos mais relevantes é que a "fenomenologia política" de Maquiavel coloca em termos precisos o problema da imagem, da aparência e suas relações com o poder. Graças a Maquiavel, é possível perceber que a destituição da falácia metafísica resulta na destituição do projeto político que lhe é associado, isto é, aquele que torna legítima a dominação por meio da fundamentação do poder no saber. Para concluir gostaria de desenvolver um pouco mais este último ponto.

O resultado evidente da falácia metafísica que atribui ao ser o status de causa da aparência é a desqualificação desta última. Por isso, ao fazer a crítica dessa falácia, em $A$ vida do espírito, Arendt se refere a uma "valorização da superfície" (ARENDT, 1978, p. 26-30), apoiando-se sobre o trabalho do biólogo Adolf Portmann, que acredita que a primazia que habitualmente concedemos à interioridade frente à exterioridade decorre de uma incompreensão da verdadeira condição dos seres vivos. Eles devem ser mais propriamente compreendidos como seres voltados para a exterioridade, orientados pela "urgência de mostrar-se" (urge of self-display) (ARENDT, 1978, p. 29). Mas a primazia do aparecer não é entendida por Arendt como uma simples inversão do ponto de vista metafísico e sim seu abandono, pois que possibilita uma nova compreensão da condição existencial dos seres vivos e, especificamente, do ser humano. Nesta nova compreensão, caduca a distinção anterior em favor de uma outra: entre aquilo que se mostra e o que não se mostra, entre aquilo que é da ordem da aparência e aquilo que é da ordem da "semblância" (semblance) (ARENDT, 1978, p. 37). Para meus propósitos, não seria conveniente aprofundar estas últimas noções, mas 
recordar que a "superfície" configura um espaço partilhado entre aquele que se mostra e aquele que vê (o espectador, ou melhor, os espectadores); o que nos traz de volta ao fundamental conceito de pluralidade.

Acredito ser importante insistir sobre esse ponto porque graças à pluralidade é possível apreender o caráter comum (isto é, coletivo) tanto da fenomenalidade, como já foi salientado, mas também do próprio poder político. Vale lembrar que um dos pontos nevrálgicos da crítica de Arendt à tradição da filosofia política é justamente a discussão em torno da natureza do poder. Na perspectiva arendtiana, ele não se confunde com nenhuma qualidade pessoal, mas, como diz a fórmula bastante conhecida, ele corresponde à "habilidade humana para agir em concerto" (ARENDT, 2000, p. 36). Em suma, trata-se de uma criação coletiva que não pode existir antes da ação; logo, não pode ser compreendido sem referência à pluralidade.

E, a meu ver, é neste ponto preciso que se ata o laço entre política e aparência: a comunidade formada por espectadores e atores é o lugar onde emerge o poder que tem a mesma natureza pública que o mundo da aparência. Dizendo de outra maneira, o poder é correlato à multiplicidade de pontos de vista. E da mesma forma que ele é incompatível com a dominação, a doxa, no domínio dos “assuntos humanos”, é incompatível com a verdade.

\section{Referências}

ABENSOUR, M. Hannah Arendt contre la philosophie politique? Paris: Sens \& Tonka, 2006.

ABENSOUR, M. La communauté politique des "tous un". Entretien avec Michel Enaudeau. Paris: Belles Lettres, 2014.

ARENDT, H. The Human condition. Chicago: The University of Chicago Press, 1958.

ARENDT, H. "Truth and Politics". In: Between past and future. Nova York: Penguin, 1968, pp. 227-64.

ARENDT, H. The life of the mind. San Diego/Nova York/Londres: Harcourt Brace Jovanovich, 1978.

ARENDT, H. On revolution. Nova York: Penguin, 1990.

ARENDT. H. "What Remains? The Language Remains: A Conversation with Günther Gauss". In: Essays in understaning - 1930-1954. Nova York: Schocken Books, 1994, pp. 123.

ARENDT, H. Sobre a violência. Trad. de A. Duarte. Rio de Janeiro: Relume Dumará, 2000 ( $2^{\mathrm{a}}$ edição). 
ARENDT, H. "Socrates". In: The promise of politics. Nova York: Schoken Books, 2005, pp. 5-39.

AUDIER, S. Machiavel, conflit et liberté. Paris: Vrin/EHESS, 2005.

DUARTE, A. Vidas em risco. Crítica do presente em Heidegger, Arendt e Foucault. Rio de Janiero: Forense Universitária, 2010.

LE NY, M. Hannah Arendt: Le temps politique des hommes. Paris: L'Harmattan, 2013.

MERLEAU-PONTY, M. "Note sur Machiavel". In: Eloge de la philosophie. Paris: Gallimard, 1989, pp. 287-308.

PORCEL, B. “Arendt e o Legado político de Cícero e Maquiavel”. In: H. ADVERSE e G. CASTELO BRANCO (org). Clássicos e contemporâneos da filosofia política. De Maquiavel a Antonio Negri. Belo Horizonte: Relicário, 2015, pp. 29-38.

ReVault D'Allonnes, M. Peut-on Parler Philosophiquement Politique? MerleauPonty et Hannah Arendt Lecteurs de Machiavel. In: G. SFEZ e M. SENELLART. Paris: PUF, 2001, pp. 179-98.

TAMINIAUX, J. La fille de Thrace et le penseur professionnel. Arendt et Heidegger. Paris: Payot, 1992.

TASSIN, E. La Question de 1'Apparence. In: ABENSOUR, M. et allii (org). Colloque Hannah Arendt. Politique et pensée. Paris: Payot, 1989, pp. 87-119.

VILLA, D. Arendt and Heidegger. The fate of the political. Princeton: Princeton University Press, 1996.

YOUNG-BRUEHL, E. Hannah Arendt. For love of the world. New Haven: Yale University Press, 1982. 